\title{
Metodologia diagnóstica e tratamento da recaída após transplante de medula óssea em paciente com leucemia promielocítica aguda
}

\author{
Ronald Pallotta ${ }^{1}$ \\ Estácio Ramos \\ Mara R. Ribeiro ${ }^{3}$
}

\begin{abstract}
O transplante de medula óssea, queéu u consagrado tratamento de várias doenças oncológicas, hematológicas e imunológicas, tem a recaída como um das principais causas de falha. As variáveis de seleção, condicionamento e de seguimento devem ser analisadas, pois influenciam de maneira fundamental tal falha.

O diagnóstico precoce da recaída tem como pilar de sustentação a capacidade de deteç̧ão a doença residual mínima. A metodologia empregada, com a citometria de fluxo, citogénetica convencional, fluorescent in situ hybridization e com o polimerase chain reaction, permite uma detecção cada vez mais precoce deste clone residual que é responsável pela volta da doença de base.

L.M.S.O, de 54 anos, teve o diagnóstico de leucemia promielocítica em 1997. Foi submetida a um transplante de medula óssea autogênico em 01/09/98 como terapêutica de con solidação. Doisanos a póso transplante demedula óssea apresentou recaída molecular diagnosticada por RT PCR realizado sequencialmente. 0 uso de ácido all-trans-retinóico foi capaz de induzir a nova remissão molecular.

0 all-trans-retinóico, que tem um mecanismo de ação não bem estabelecido na indução da remissão completa na LMA M3, pode ser utilizado em recaídas. No caso apresentado o diagnóstico precoce a partir de um esquema de avaliação póstransplante bem programado permitiu um bom resultado. Conclui-sequeas variáveis de seleção, condicionamento e seguimento devem ser muito bem estudadas para planejar um acompanhamen to adequado e prolongado apóso transplante demedula óssea, permitindo cada vez mais melhores resultados com o procedimento.
\end{abstract}

Rev.bras.hematol.hemoter., 2000, 22(3): 414-418

Palavras-chave: Leucemia, leucemia promielocítica, transplante de medula óssea

\section{Introdução}

O transplante de medula óssea (TMO) é um tratamento efetivo para doenças oncológicas, hematológicas e imunológicas. Porém, a recaída, ou seja, a volta da doença de base, é uma das principais causas de falha desta opção terapêutica (1).
As variáveis que influenciam a incidência de tal processo podem ser divididas em variáveis de seleção, condicionamento e de seguimento.

Dentre as variáveis de seleção, incluem-se a fase da doença em que o paciente se encontra quando do transplante, 0 tempo entre 0 diagnóstico e o TMO, bem como o tratamento prévio recebido.

1 - Médico hematologista especialista em tran splante de medula óssea, coordenador do programa de transplante de medula óssea da Real Sociedade Beneficência Portuguesa - XVI de Setembro, Salvador, BA e coordenador da equipe médica da unidade de transplante de medula óssea do Hospital Prof. Jorge Valente, Salvador, BA

2 - Médico hematologista, patologista-clínico, diretor médico do Timo Medicina Laboratorial

3 - Médica hemoterapeuta do Instituto de Hemoterapia da Bahia (IHEBA)

Correspondência para: Dr. Ronald Pallotta

Rua Agn elo de Brito, 187, $2^{2}$ andar, conj 202. Salvador. BA. CEP: 40170-100

E-mail: rpallotta@e-net.com.br

Fone: (71) 247-3033. Fax: (71) 247-3223 
Nas variáveis de condicionamento, incluem-se os esquemas de quimioterapia associado ou não à radioterapia empregados na preparação do transplante de medula óssea.

Finalmente nas variáveis de seguimento, incluem-se o tipo de TMO, tipo de profilaxia e de ocorrência da doença enxerto contra hospedeiro (GVHD).

Após um TMO bem sucedido, a hematopoese e a imunidade são reconstituídas a partir de células do doador (no caso dos transplantes autogênicos doador e receptor são a mesma pessoa, o paciente). A recaída geralmente ocorre em células do receptor e pode ser explicada por mecanismos nos quais clones de células do paciente conseguem superar as altas doses de quimioterapia e/ou radioterapia do condicionamento. No caso dos transplantes alogênicos, estes clones sobrevivem ainda ao efeito anti-tumoral do novo enxerto. Existem raros relatos onde a recidiva ocorre em células do doador nos TMO alogênicos. As explicações, embora ainda no terreno especulativo, se baseiam em teorias de vírus tumorigênicos latentes, microambiente alterado e de células susceptíveis $(2,3)$.

0 diagnóstico e o prognóstico da recidiva se baseiam na capacidade de se diagnosticar a doença residual mínima (DRM), ou seja, de se detectar a quantidade de células tumorais que se mantém viáveis após ser atingida a remissão completa. A metodologia de detecção pode ser por citometria de fluxo, citogenética, $\operatorname{FISH}$ ou $\operatorname{PCR}(4,5)$.

A citometria de fluxo é um teste de imunofenotipagem que permite determinar através de antígenos de superfície clones celulares ( $C D=$ cluster differenciator). Desta forma, com 0 conhecimento prévio das características das células anômalas podem ser encontrados sinais de clones residuais em uma massa tumoral de até $10^{9}$ células, sugerindo DRM. É uma metodologia mais sensível que as análises mofológicas e histológicas que permitem identificar uma massa tumoral de no mínimo $10^{11}$ células .

A citogenética convencional, através da análise do cariótipo, é altamente específica porém não é sensível. Este teste possui uma sensibilidade de detectar uma célula em cada 100 células, mas sua metodologia só permite analisar quando estas se encontram em metáfase. Desta forma, fatores como crescimento celular adequado, bem como conhecimento de alterações prévias são primordiais na detecção da DRM por este método (6).

A fluorescent in situ hybridization (FISH) é um potente método para localizar sequência de ácidos nucléicos em células frescas ou congeladas. A hibridação in situ tem uma alta sensibilidade podendo avaliar uma célula em 1000 células. Sua metodologia quantitativa permite analisar células tanto em metáfase como em intérfase, evidenciando a região do genoma por meio de substância fluorescente. Esta detecção precoce de alterações cromossômicas podem orientar no diagnóstico precoce da recaída (7).

A polimerase chain reaction ( $P C R$ ) é uma técnica introduzida por Saiki e colaboradores em 1985 como um procedimento que possibilitaria a amplificação de certas regiões do genoma em até 100.000 vezes ou mais através de uma reação in vitro. É uma técnica simples que depende do conhecimento da sequência exata de DNA, ou parte dela a ser amplificada. 0 requisito básico é um par de oligonucleotídeos chamados iniciadores (primers), complementares às sequências das extremidades da dupla fita de DNA a ser amplificada. A região que é amplificada fica entre estas duas extremidades. Possui uma alta sensibilidade, detectando 1 célula em $10^{6}$ células. Porém, pode detectar células residuais que apresentem transcrições imaturas podendo, em alguns casos, levar anos até serem erradicadas. Desta forma um acompanhamento seqüencial se mostra fundamental na detecção de recaída por esta metodologia (8).

Neste relato de caso uma análise sequenciada de PCR permitiu a detecção precoce da recidiva possibilitando que uma opção terapêutica não agressiva modificasse a história natural deste processo.

\section{Relato do Caso}

L.M.S.O, 54 anos, sexo feminino, natural e procedente de Salvador teve diagnóstico de leucemia mielóide aguda (FAB M3) em setembro de 1997.

Recebeu tratamento quimioterápico caracterizado por dois ciclos de Arabinosideo 
C, Idarrubicina e Etoposide atingindo remissão completa. Ficou sem acompanhamento até julho de 1998, quando procurou serviço médico. Nesta época mostrou mielograma e citogénetica normais, porém pesquisa da $\mathrm{t}(15 ; 17)$ (q 22; $\mathrm{q}$ 21) na medula óssea positiva.

Devido tratamento irregular prévio foi realizado purging in vivo com ciclofosfamida e posteriormente consolidação com transplante de medula óssea autogênico em 01/09/98. Foi utilizado irradiação corporal total (TBI) e Melfalan como esquema de condicionamento.

0 transplante cursou sem intercorrências, a recuperação medular ocorreu no dia +20 após a paciente ter recebido $3,04 \times 10^{8}$ células nucleadas por quilograma de peso (1,54 × 106 CD $34+/ \mathrm{kg}$ ). Apresentou mucosite grau 1 e teve febre de origem indeterminada por dois dias, que cedeu com o uso de antibioticoterapia de amplo espectro. A evolução no pós transplante tardio teve como característica a presença de pseudo-GVHD limitado em pele que apresentou regressão espontânea em seis meses após TMO.

0 seguimento com biologia molecular mostrou RT-PCR em outubro de 1998 (30 dias após TMO) e em setembro de 1999 (1 ano após TMO) negativos.

Em setembro de 2000, 2 anos após o TMO, em exame de rotina a pesquisa da $\mathrm{t}(15 ; 17)(\mathrm{q} 22 ; \mathrm{q} 21)$ se mostrou positiva na segunda etapa denominada nested com sensibilidade de $10^{4}$ a $10^{6}$.

Como a conhecida translocação do gene funcional PML/RARA era inicialmente positiva e se negativou com o transplante, neste exame mostrou uma repositivação desta forma foi considerada como recaída molecular.

Tendo em vista a paciente nunca ter recebido terapêutica com ácido all-transretinóico foi optado por se introduzir dose diária de $40 \mathrm{mg} / \mathrm{m}^{2}$ de tretinoína (vesanoid ${ }^{\circledR}$ ) pelo período de 4 semanas.

$\mathrm{Na}$ reavaliação do tratamento a pesquisa por RT-PCR da t(15;17) se mostrou negativa nas duas fases do RT-PCR.

\section{Conclusão}

A recidiva após transplante de medula óssea é um obstáculo a ser vencido, principalmente pelo fato que para muitos esta terapêutica é a ultima chance de se atingir a tão almejada cura.

Atualmente com o desenvolvimento de técnicas de detecção da DRM, tornou-se extremamente precoce o diagnóstico da recaída o que permite uma abordagem mais adequada.

A manipulação da recidiva pode ser através de imunomodulação utilizando o efeito antitumoral do enxerto nos transplante alogênicos. Para tal uma exacerbação do GVHD com a retirada precoce da imunossupressão (9) ou ainda a infusão de linfócitos do doador (10) pode ser utilizada.

O utra opção é a utilização de drogas como o interferon alfa na leucemia melóide crônica (11), a interleucina 2 na leucemia melóide aguda (12) ou, como neste caso, o ácido all-transretinóico na leucemia promielocítica.

0 ácido all-trans-retinóico (ATRA) é um metabólito do rotinol e pertence à classe dos retinóides, que compreende análogos naturais e sintéticos. Estudos com ATRA in vitro demostraram indução de diferenciação e inibição de proliferação celular em linhagens de células hematopoiéticas transformadas, incluindo as linhagens das células leucêmicas mielóides humanas. 0 mecanismo de ação na leucemia promielocítos aguda (LMA M3) não é conhecido podendo ser devido a uma alteração na ligação do ácido all-trans-retinóico a um receptor no núcleo celular do ácido retinóico (RAP) uma vez que o receptor do ácido retinóico é alterado pela fusão com a proteina chamada LPM (13).

Ele é indicado para indução da remissão em leucemia promielocítica aguda (LMA M3). Pacientes não tratados anteriormente, bem como pacientes que recaíram depois da quimioterapia padrão (antraciclinicos e arabinosídeo $\mathrm{C}$ ou tratamentos similares) ou pacientes que são refratários a qualquer quimioterapia devem ser tratados com ácidos all-trans-retinóico. A associação de quimioterapia ao ATRA aumenta a duração da sobrevida e reduz o risco de recidiva quando comparado a quimioterapia isoladamente. A terapia de manutenção está ainda em investigação, entretanto a perda da capacidade de resposta ao ácido foi relatada entre os pacientes mantidos somente com ácido all-trans-retinóico $(13,14)$. 
Neste caso os fatores que contribuíram para uma boa resposta foram as avaliações das variáveis que influenciam a recaída. $A$ análise do tratamento prévio, uma vez que a paciente nunca recebeu ATRA como parte de seu esquema terapêutico, bem como uma programada investigação de DRM a partir de estudos sequenciados de RT-PCR foram fundamentais. Estes dados permitem concluir que para o TMO atingir bons resultados é necessário além de uma indicação precisa um planejamento estratégico rigoroso. Desta forma um acompanhamento adequado e prolongado após o procedimento permite elaborar estratégias terapêuticas precoces para o tratamento da principal causa de falha, a recaída.

\section{Diagnostic methodology and treatment of relapseafter bonemarrow transplantation in a patient with acute promyelocitic leukemia} Ronald Pallotta, Estácio Ramos, Mara R. Ribeiro

\footnotetext{
Abstract

Bone marrow transplantation is a well established modality of treatment for oncologic, hematolologic and immunologic diseases, however the recurrence is the main cause of treatment failure. The variables regarding to selection, conditioning and follow up should be analyzed since them can influence it in a fundamental manner.

The early diagn osi s of relapse is susten ted by the ability to detect the minimal residual disease. The methodology using flowcitometry, conventional cytogenetic, fluorescence in situ hybridization (FISH) and polymerase chain reaction ( $P C R$ ) allow the diagnosis of these residual clone that are responsible for relapse. L.M.S.O., 54 year old lady, was diagnosed with promyelocitic leukemia (AML M3) in 1997. She was submitted to an autologous bone marrow transplantation in 09/01/98 as consolidation therapy. Two years after the transplant she was diagnosed with a molecular relapse by RT-PCR sequentially performed. The use of all-transretinoic acid (ATRA) was able to induce a new molecular remission.

The mechanism of action of ATRA to induce remission in AML M3 is not well established. This drug can be use in relapse. In the case that was
}

presented, the early diagnosis that leaded to this good result happened because of a well planned post transplant evaluation. These variables of selection, conditioning and follow up should be well studied to plan an adequate and prolonged post transplant follow up, allowing better results with the procedure.

Rev.bras.hematol.hemoter.,2000,22(3):414-418

Key words: Leukemia, promyelocitic leukemia, bone marrow transplantation

\section{Referências Bibliográficas}

1. Armitage, J.O. BoneMarrow Transplantation, NEJM. 1994; 330 (12): 827-838.

2. Barret, A. J. et al. Bone Marrow Transplantation for Acute Lymphoblastic Leukemia: factors influencing relapse and survival. Blood. 1989; 74: 862

3. Mourratidou, M. et al. Recurrence of acute leukemia in donor cells after bone marrow transplantation: documantation by in situ DNA hybridization. BMT 1993; 12: 77-80.

4. Hughes, T. et al. Detection of residual leukemia after bone marrow transplant for chronic myeloid leukemia: role of polymerase chain reaction in predicting relapse. Blood 1991; 77: 874-878.

5. Thompson, J. et al. Molecular quantification or residual disease in crhonic myelogenous leukemia after bone marrow transplantation. Blood 1992,79: 1629-1635.

6. Wessman, M. et al. Detection of residual host cells after bone marrow transplantation using non isotopic in situ hybridization and kariotype analysis. BMT. 1993; 11: 279-284.

7. Bentz, M. Fluorecense in situ hybridization in leukemias: "The FISH are spawning" Leukemia. 1994; 8: 1447-1452.

8. Brock, D.G.H. The polymerase chain reaction. Molecular gen eticsfor the clinician. New York, Cambridge, 1993, pg. 52-6: The polimerase chain reaction.

9. Higano, C.S. et al. Durable complete remission of acutenon-lymphoblastic leukemia associated with discontinuation of immunossupression following relapse after BMT: a case report of a probable graft-versus-leukemia effect. 
Transplantation. 1990, 50: 175-177.

10. Sullivan, K et al. Graft versus host disea se as adoptive immunotherapy in patients with advanced hematologic neoplasm. NEJM. 1989; 320: 828-832.

11. Higano, C. et al. Use of interferon alpha for the treatment of relapse of chronic myelogenousleukemia in chronic phase after allogeneic bone marrow transplantation. Blood. 1992; 80: 1437-1441.

12. Charak, B.S. et al. Interleukin-2 in bone marrow transplantation: preclinical studies. BMT. 1992; 10: 103-111.

13. Chen, Z.X. et al. A clinical and experimental study on all-trans-retinoic-acid treated acute promyelocytic leukemia patients. Blood. 1991; 78: 1413-1419.

14. Smith et al. Retinoids in cancer therapy. JCO. 1992; 10: 839-864.

Recebido: $15 / 10 / 2000$

Aceito: $01 / 12 / 2000$ 